$11-1-2007$

\title{
Does Teacher Preparation Matter for Beginning Teachers in Either Special or General Education?
}

\author{
Ed Boe \\ Univer. of Pennsylvania, boe@gse.upenn.edu \\ Sujie Shin \\ University of Pennsylvania \\ Lynne H. Cook \\ California State University
}

Follow this and additional works at: https://repository.upenn.edu/gse_pubs

\section{Recommended Citation}

Boe, E., Shin, S., \& Cook, L. H. (2007). Does Teacher Preparation Matter for Beginning Teachers in Either Special or General Education?. Retrieved from https://repository.upenn.edu/gse_pubs/186

\footnotetext{
Copyright (C) 2008 by Hammill Institute on Disabilities. Sage Collections. Postprint version. Published in Journal of Special Education, Volume 41, Issue 3, November 2007, pages 158-170.

Publisher URL: http://sed.sagepub.com/cgi/reprint/41/3/158

This paper is posted at ScholarlyCommons. https://repository.upenn.edu/gse_pubs/186

For more information, please contact repository@pobox.upenn.edu.
} 


\title{
Does Teacher Preparation Matter for Beginning Teachers in Either Special or General Education?
}

\author{
Abstract \\ The current U.S. Department of Education (USDOE) emphasis on the preparation of teachers in content \\ knowledge, and de-emphasis on pedagogy and teaching practicums, constitutes a major issue \\ concerning how best to prepare a sufficient supply of highly qualified teachers. By contrast, federal policy \\ represented by the 2001 No Child Left Behind Act (NCLB) emphasizes both full certification and content \\ knowledge. Our research was based on data from the Schools and Staffing Survey for beginning teachers \\ in both special and general education (separately). Results showed that extensive preparation in \\ pedagogy and practice teaching was more effective than was only some or no preparation in producing \\ beginning teachers who (a) were fully certified, (b) secured in-field teaching assignments, and (c) reported \\ being well prepared to teach subject matter and well prepared with respect to pedagogical skills. Thus, \\ contrary to the USDOE perspective emphasizing preparation in content knowledge, extensive preparation \\ in pedagogy and practice teaching contributed to the attainment of the two key NCLB indicators of a \\ highly qualified teacher: full certification and in-field teaching.
}

\section{Comments}

Copyright $@ 2008$ by Hammill Institute on Disabilities. Sage Collections. Postprint version. Published in Journal of Special Education, Volume 41, Issue 3, November 2007, pages 158-170.

Publisher URL: http://sed.sagepub.com/cgi/reprint/41/3/158 


\title{
Does Teacher Preparation Matter for Beginning Teachers in Either Special or General Education?
}

\section{Erling E. Boe and Sujie Shin}

University of Pennsylvania

Lynne H. Cook

California State University, Dominguez Hills

\begin{abstract}
The current U.S. Department of Education (USDOE) emphasis on the preparation of teachers in content knowledge, and de-emphasis on pedagogy and teaching practicums, constitutes a major issue concerning how best to prepare a sufficient supply of highly qualified teachers. By contrast, federal policy represented by the 2001 No Child Left Behind Act (NCLB) emphasizes both full certification and content knowledge. Our research was based on data from the Schools and Staffing Survey for beginning teachers in both special and general education (separately). Results showed that extensive preparation in pedagogy and practice teaching was more effective than was only some or no preparation in producing beginning teachers who (a) were fully certified, (b) secured in-field teaching assignments, and (c) reported being well prepared to teach subject matter and well prepared with respect to pedagogical skills. Thus, contrary to the USDOE perspective emphasizing preparation in content knowledge, extensive preparation in pedagogy and practice teaching contributed to the attainment of the two key NCLB indicators of a highly qualified teacher: full certification and in-field teaching.
\end{abstract}


Upon reviewing "scientifically rigorous" evidence (from Goldhaber \& Brewer, 1999; Walsh, 2001) in a report on teacher quality, the U.S. Department of Education (USDOE) concluded that teacher preparation was of little or no demonstrated value for enhancing student achievement (USDOE, 2002). This conclusion about the value of teacher preparation applied both to traditional and alternative teacher preparation. Traditional teacher preparation (TTP) leads to degrees from colleges and universities and entails unpaid practice teaching. Alternative teacher preparation (ATP) typically targets individuals with degrees who seek a fast-track route to fulltime paid teaching employment. ATP programs vary widely in the amount of preparation provided and in their institutional sponsorship (Feistritzer, 2005; Rosenberg \& Sindelar, 2005). According to the USDOE (2002), neither attendance at traditional schools of education nor teacher certification improved student achievement. Likewise, with respect to ATP programs, the USDOE's position was that "further research is required to provide evidence of their effectiveness" (2003, p. 21). With respect to the production of qualified teachers, the USDOE report stated that the "best available research shows that solid verbal ability and content knowledge are what matters most” (2002, p. 9).

With the passage of the No Child Left Behind Act (NCLB) of 2001, the topic of teacher quality has been spotlighted. According to the USDOE (2002), the NCLB definition of a "highly qualified teacher" (HQT) focuses on content knowledge. In accordance with this interpretation, the USDOE promoted improvements in teacher qualifications by emphasizing content knowledge in teacher preparation and professional development (see also USDOE, 2003, 2004; White House, 2002). An emphasis on preparation in content knowledge applies to special education teachers (SETs) as well, as has been made explicit in the Individuals with Disabilities Education Improvement Act (IDEIA) of 2004.

In view of its perspective that verbal ability and content knowledge matter most in the production of qualified teachers, the USDOE concluded, "Schools of education and formal teacher training programs are failing to produce the types of highly qualified teachers that the No Child Left Behind Act demands" (2002, p. viii). This failure is attributed to the "burdensome requirements" of a "shocking number of education courses" and the fact that many ATP programs in this respect are "just as burdensome as their more traditional cousins" (p. 31). Instead, the USDOE report called for "fast track"ATP programs leading to certification that shorten or eliminate "course work in education philosophy or methods, pedagogy, practice teaching, etc." (p. 15). According to the USDOE, this new approach "would not necessarily mean the end of schools of education," especially if they were reconceptualized and reorganized "to resemble graduate schools of business" (p. 20). Thus, except for fast-track ATP programs, the challenge to all teacher preparation is clear. In summary, the USDOE contended that extensive preparation in pedagogy (provided by either TTP or ATP programs) is counterproductive in producing HQTs as defined and required by federal policy in NCLB.

However, the USDOE's interpretation of NCLB as focused on preparation in content knowledge overlooks NCLB's other focus on full certification. Under the mandate of NCLB, all elementary teachers, and secondary teachers of core academic subjects, must have been highly qualified by the end of the 2005-2006 school year. The two key requirements defining HQTs are full state certification and a high level of content knowledge (almost all teachers satisfy the third requirement - namely, must earn at least a bachelor’s degree; USDOE, 2002, pp. 4-5). 
Nonetheless, the USDOE report said that NCLB focuses on "content knowledge, as opposed to components such as pedagogy or teaching practicums" (p. 6). Yet, the report recognized that qualifying for full certification requires extensive coursework in pedagogy and practice teaching.

Thus, there is a contradiction between formal federal policy (i.e., NCLB) defining an HQT (certification and content knowledge), and the USDOE's (2002) position on what matters most in the production of qualified teachers (verbal ability and content knowledge). If the USDOE perspective were federal policy, then the two defining requirements for an HQT in NCLB would have been solid verbal ability and content knowledge.

This contradiction between the requirements of NCLB and the USDOE perspective represents a quandary for teacher preparation programs. In preparing HQTs for U.S. public schools, should available resources be invested in making content knowledge the dominant emphasis, with a concomitant de-emphasis on pedagogy and teaching practicums, as the USDOE advocates? This is a significant issue regarding the design of both TTP and ATP programs in producing the certified teachers required by states to fill positions in public schools.

TTP and ATP programs have in common the provision of instruction in pedagogy and supervised classroom-teaching experience. What varies for both types is the amount of and components included in preparation, as represented by "methods courses, field experiences, supervision, and mentorship” (Sindelar, Daunic, \& Rennells, 2004, p. 210). Traditional programs typically provide extensive instruction in pedagogy and practice teaching (National Association of State Directors of Teacher Education and Certification, 2003), whereas ATP programs are much more variable in the amount of instruction provided in pedagogy (Feistritzer, 2005; Rosenberg \& Sindelar, 2005). According to several reviews of research (Brownell, Hirsch, \& Seo, 2004; Rosenberg \& Sindelar, 2005; Sindelar et al., 2004), ATP programs providing intensive preparation in these respects tend to produce more effective teachers.

According to the USDOE, research evidence is weak on the value of training in pedagogy or time spent in practice teaching; therefore, the USDOE recognized a need for continued research on teacher quality (2003). As might be expected, the USDOE's conclusions about the ineffectiveness of teacher preparation and certification have been challenged by other reviews of relevant research (e.g., Darling-Hammond \& Youngs, 2002). Additional empirical research has demonstrated that extensive preparation produces more qualified teachers than does lesser amounts of preparation. For example, two studies of SETs in several school districts (Nougaret, Scruggs, \& Mastropieri, 2005; Sindelar et al., 2004) compared the effectiveness of various types of teacher preparation (including both TTP and ATP programs) in terms of instruction and classroom management, by observation of classroom teaching and by teacher self-reports of preparedness to teach. These studies have generally shown that extensive teacher preparation produced more effective teachers than did lesser preparation, regardless of the type of preparation.

Similarly, the results of research on general education teachers (GETs) in a large school district (Darling-Hammond, Chung, \& Frelow, 2002) indicated that more extensively prepared teachers from traditional programs reported being significantly better prepared to teach subject matter, develop curriculum, and handle classroom management than did teachers who were much less 
prepared to teach. Other research, also at the school-district level, has provided considerable evidence that fully certified teachers (who have extensive teacher preparation) produce higher student achievement scores than do undercertified teachers (who typically have much less preparation; Darling-Hammond, Holtzman, Gatlin, \& Heilig, 2005; Laczko-Kerr \& Berliner, 2002). Thus, studies with SETs and with GETs have both shown that extensive teacher preparation produced more effective teachers than did lesser preparation.

In light of the controversy over the value of extensive teacher preparation recently intensified by the 2002 USDOE report, more research (including national-level research) is needed about the teacher qualification outcomes of various amounts of preparation in pedagogy and supervised teaching. If such preparation is important, the amount of preparation should be related to better outcomes regardless of the type of preparation (i.e., TTP or ATP). If, on the other hand, the amount of instruction in pedagogy and supervised teaching is not important, the amount of preparation should not be related to better outcomes. The results of such research are directly relevant to the issue about the value of teacher preparation in pedagogy and teaching practicums for producing HQTs, as raised by the USDOE report.

Accordingly, the purpose of this research was to investigate relationships between the amount of teacher preparation (categorized as extensive, some, or little/none) and several teacher qualification indices, using national data produced by the 1999-2000 Schools and Staffing Survey (SASS). Specifically, we investigated the following central research questions for SETs and GETs (separately) in their first 5 years of employment:

- To what extent is the amount of teacher preparation associated with the two key dimensions of an HQT as defined by NCLB: full certification and earning a degree major in a teacher's main teaching assignment?

- To what extent is the amount of teacher preparation associated with other dimensions of teacher qualifications: field of degree major in relation to teaching field, degree level, and each of six aspects of being well prepared to teach? This research provides a unique perspective on teacher qualification variables associated with the amount of teacher preparation, regardless of whether obtained by traditional or alternative means. It also provides additional research evidence on the preparation of HQTs, as called for by the USDOE (2003).

\section{Method}

\section{Data Source}

The data source was teachers’ self-reports to the Public School Teacher Questionnaire (PSTQ) a component of SASS (1999/2000), conducted by the National Center for Education Statistics (NCES), USDOE. The PSTQ provided information directly relevant to this research, such as the amount of preparation in pedagogy and practice teaching (extensive, some, or little/none) and teacher qualifications (e.g., certification status).

\section{Teachers Studied}

Definition of Teacher. In keeping with the SASS definition, a teacher was any individual who reported being employed either full-time or part-time at a public school with a main assignment teaching in any grade kindergarten to 12, including itinerant teachers and long-term substitutes. 
Excluded from this definition of a teacher were individuals who identified their main assignment as pre-kindergarten teacher, short-term

substitute, student teacher, teacher aide, or a non-teaching specialist of any kind.

Definitions of Special and General Education Teachers. The PSTQ asked teachers to designate one of 64 "main teaching assignment fields" as "the field in which you teach the most classes.” We grouped these 64 fields into two main areas: special education and general education. Special education included 15 main teaching assignment fields, such as deaf and hardof-hearing, developmentally delayed, and learning disabilities. All teachers who designated 1 of these 15 fields as their main teaching assignment were defined as SETs. Given that the PSTQ included a category for "other special education," all elementary and secondary teachers with a main assignment in any area of special education should have been able to identify themselves as such, regardless of the particular certification terminology used in their home state. GETs were then defined as all public school teachers $(\mathrm{K}-12)$ other than SETs.

Teacher Sample. The 1999-2000 PSTQ provides nationally representative estimates of the numbers of public school teachers of the various types analyzed in this research. Specifically, PSTQ data were obtained from a large national probability sample of public school teachers $(N=$ 53,105 , including public charter school teachers) with a weighted questionnaire response rate of $83 \%$. This yielded a sample of 44,896 K to 12 teachers who completed the PSTQ. Of this, a subsample of 10,952 teachers in their first 5 years of teaching employment (termed beginning teachers) was used in this research. Of these beginning teachers, 1,214 were SETs and 9,738 were GETs. There are no missing data for completed PSTQs because NCES imputed values for item non-response. More detailed information about the 1999-2000 SASS is provided by Tourkin et al. (2004).

\section{Design}

The research was designed to analyze, from a national perspective, relationships between the amount of teacher preparation (extensive, some, or little/none) and variation in several qualifications of beginning SETs and GETs (separately) who practiced in public schools during the 1999-2000 school year. Beginning teachers are defined as being in their 1st through 5th years of employment as being regular, itinerant, or long-term substitute teachers (full- or parttime). Specifically, we examined relationships between amount of teacher preparation (the independent variable) and five teacher qualifications

(dependent variables). A description of these variables follows.

Amount of Teacher Preparation. Teachers differ widely in the amount of preparation in pedagogy and supervised teaching they complete. PSTQ provides information for each beginning teacher that can be used to define three ordered categories of the amount of teacher preparation completed (extensive, some, or little/none). One item of information available is the length of the practice teaching experience: 10 weeks or more, 5 to 9 weeks, 1 to 4 weeks, or no practice teaching. Other items of information available are completion of each of four common components of teacher preparation: (a) coursework in selecting and adapting instructional materials, (b) coursework in educational psychology, (c) observation of other classroom teaching, and (d) received feedback on their teaching. Completion of extensive practice teaching 
and each of these common components are ordinarily required by states for teachers to become certified. According to data from 50 states and from Washington, DC, produced by the National Association of State Directors of Teacher Education and Certification (NASDTEC), 8 weeks of practice teaching is the minimum required for an initial teaching certificate (NASDTEC, 2003, Table B-8). Information from the American Association of Colleges for Teacher Education also indicates that 8 weeks of practice teaching is about the minimum that member colleges require in their TTP programs (D. Imig, director, personal communication, April 7, 2003). In addition, almost all states require coursework in the psychological foundations of teaching, teaching methods, and field experience prior to student teaching (NASDTEC, 2003, Tables B-5, B-6, B7). Given this background and using particular combinations of (a) length of the practice teaching experience and (b) number of four common components of teacher preparation completed, it was possible to define operationally three amounts of teacher preparation in pedagogy and practice teaching, as follows:

1. Extensive Teacher Preparation. Extensive teacher preparation was defined as completing (a) 10 or more weeks of practice teaching along with all four of the common components of TTP listed above, (b) 10 or more weeks of practice teaching and three of the four common components of TTP, (c) 10 or more weeks of practice teaching and less than three of the four common components of TTP, or (d) 5 to 9 weeks of practice teaching along with all four common components of teacher preparation. The percentages of teachers classified as completing extensive preparation according to each of these criteria are $75 \%, 10 \%, 2 \%$, and $12 \%$, respectively.

2. Some Teacher Preparation. Some teacher preparation was defined as completing (a) 5 to 9 weeks of practice teaching and some of the four common components of TTP listed above, (b) 1 to 4 weeks of practice teaching and all or some of the four common components of teacher preparation, or (c) no practice teaching but all four common components of teacher preparation. The percentages of teachers classified as completing some preparation according to each of these criteria are $29 \%, 27 \%$, and $44 \%$, respectively. Only $11 \%$ of teachers classified here completed less than three of the four common components of teacher preparation.

3. Little or No Teacher Preparation. All other teachers without practice teaching were defined as having little or no teacher preparation. Of teachers classified as completing little or no preparation, $26 \%$ did not complete any of the four common components of teacher preparation listed above, while $74 \%$ completed from one to three of these four components.

Teacher Qualification Variables. Five teacher qualifications were defined so that their relationships with the teacher preparation variable could be examined:

\section{Certification in Main Teaching Assignment.}

The PSTQ asked teachers to identify (a) their "main teaching assignment field" from a list of 64 fields (i.e., the field in which a teacher instructs the most classes) and (b) the type of certificate held in this field. Teachers were classified as "fully certified" if they held an advanced professional certificate, regular or standard state certificate, or a probationary certificate (the 
initial certificate issued after satisfying all requirements except the completion of a probationary period) in their main teaching assignment field. Unless thus fully certified, teachers were classified as "partly certified." This could be due to being fully certified in some other teaching field; or holding a provisional, temporary, emergency, or other certificate; or having a waiver of certification; or not being certified in any form. Being fully certified is regarded as the higher qualification. PSTQ recognizes that many states certify SETs noncategorically. Each SET is asked to designate her or his main teaching assignment and certification area in special education from a list of 15, one of which is "special education, general."

2. In- and Out-of-Field Teaching Assignment. The PSTQ asked teachers to identify (a) their "main teaching assignment field" from a list of 64 fields and (b) their major fields of study for each bachelor's or postgraduate degree earned. If a teacher's major field of study (e.g., learning disabilities or mathematics) at the bachelor's or postgraduate degree levels corresponded with his or her main teaching assignment field (e.g., learning disabilities or mathematics), the teacher was classified as "teaching infield." If there was no such correspondence, the teacher was classified as "teaching out-of-field." Teaching in-field is regarded as the higher qualification. We adopted the list of such “correspondences” used by the NCES (Seastrom, Gruber, Henke, McGrath, \& Cohen, 2002) and expanded it to include the main assignment fields in special education and vocational education.

3. Degree Major Field. Teachers were also classified according to the academic or professional field(s) in which they had majored through December 1999. Teachers with one or more degree majors in any field of teacher preparation in special education (e.g., learning disabilities), at the bachelor's or master's degree levels, were classified as having a special education major. Similarly, teachers with one or more degree majors in any field of teacher preparation in general education (e.g., mathematics education), at the bachelor's or master's degree levels, were classified as having a general education major. Teachers with majors in a field of teacher preparation in both special education and in general education were classified as having majored in the field of their main teaching assignment. All teachers who did not major in a field of teacher preparation were classified as having other degree majors (e.g., mathematics).

4. Degree Level. The PSTQ asked teachers to identify all the degrees they had earned. If a teacher had earned only a bachelor's degree or lower (a small percentage earned an associate of arts or no degree), they were classified as having earned a "bachelor's or lower degree." Otherwise, a teacher was classified as having earned a "master's or higher degree."

5. Teacher Reports of Being Well Prepared to Teach. Seven dimensions of being "well prepared to teach" were defined. Teachers were asked to rate how well prepared they were on a four-point scale (not at all prepared, somewhat prepared, well prepared, very well prepared). We classified teachers as "well prepared" (coded 1), separately for each of seven respects, if they answered either "well prepared" or "very well prepared" to the following question: In your first year of teaching, how well prepared were you to: (a) teach your subject matter, (b) select and adapt curriculum and instructional materials, (c) plan lessons effectively, (d) use a variety of instructional methods, (e) assess students, (f) handle a range of classroom management or discipline situations, and (g) use computers in instruction? Otherwise, teachers were classified as "not well prepared" (coded 0). 


\section{Analysis Procedures}

Based on the sample of beginning teachers completing the PSTQ, national estimates of the numbers of teachers of each type included in the design (along with percentages and standard errors) were computed by special procedures developed by NCES for complex sample survey data (Tourkin et al., 2004). The national estimates of each type of teacher, the sample sizes on which these estimates were based, and their standard errors, are provided in Appendices A and B of Boe, Shin, and Cook (2005).

Chi-square tests of the statistical significance of relationships between each teacher qualification and the teacher preparation variable were performed separately for SETs and GETs on the nationally estimated numbers of beginning teachers. In addition, the teacher preparation variable and three teacher qualification variables were used as predictor variables in a logistic regression model for each of six dimensions of being well prepared as a beginning teacher. Measures of the magnitude of association (i.e., effect size) produced by logistic regression analysis are represented by odds ratios (OR).

\section{Results and Discussion}

As shown in Figure 1, a substantial majority of beginning SETs nationally in 1999-2000 had extensive teacher preparation in pedagogy and practice teaching (83\%, representing 67,000 SETs). A minority had only some teacher preparation (12\%, representing 10,000 SETs), while another minority had essentially no teacher preparation (5\%, representing 4,000 SETs). As seen, the percentage of beginning SETs completing only some teacher preparation (12\%) was one third greater than the comparable percentage of beginning GETs (9\%; $p<.05$, two-tailed). This difference suggests that teacher shortages in special education have been addressed, in part, by hiring less extensively prepared teachers than those hired in general education.

In defining extensive preparation, we used information provided by PSTQ about the length of practice teaching (an unpaid supervised experience provided by traditional programs, but not by ATP programs). In contrast, ATP programs typically provide participants with full-time employment as teachers (a paid supervised experience). Based on further analyses, it appears that many ATP participants regarded their full-time paid employment as equivalent to practice teaching when they answered the practice teaching question. Accordingly, our category of extensive teacher preparation includes both TTP graduates and ATP completers. Unfortunately, PSTQ did not provide sufficient data for a separate analysis of broad types of teacher preparation (TTP, ATP, none), thereby precluding analyses of amount of preparation by type. As observed by Sindelar et al. (2004) and Brownell et al. (2004), the intensity of teacher preparation has been shown in other research to produce effective teachers regardless of whether preparation was obtained by TTP or ATP programs. 


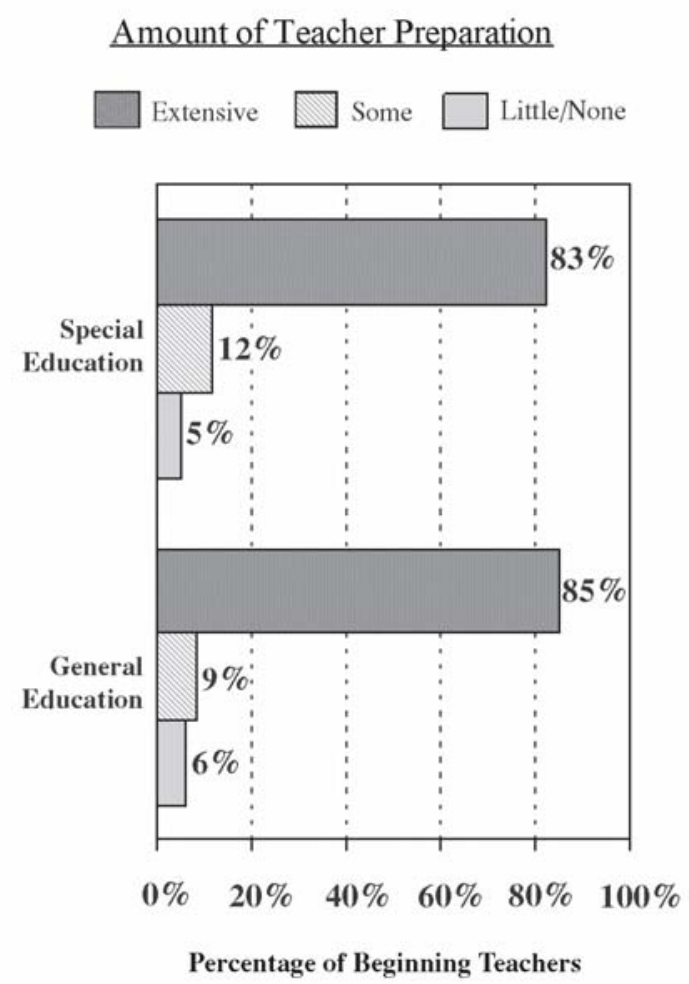

FIGURE 1. Percentage of beginning teachers in special and general education by amount of preparation. The amount of preparation by teaching field $(3 \times 2) \chi^{2}$ was $17.30(p<.0001)$. Data source: The 1999-2000 Schools and Staffing Survey, NCES, USDOE.

Thus, a high percentage of beginning SETs and GETs completed extensive and often costly (in time and resources) preparation in pedagogy and supervised teaching. It is therefore worth knowing whether different amounts of preparation (i.e., extensive, some, or little/none) yielded more qualified teachers.

\section{Do Teacher Qualifications Vary by Amount of Teacher Preparation? Certification in Main} Teaching Assignment. As seen in Table 1, 75.2\% of beginning SETs with extensive preparation in pedagogy and supervised teaching were fully certified in their main teaching assignment, a level much higher than that for SETs with only some preparation (33.0\%) and for SETs without preparation (14.2\%). As should be expected, these differences demonstrate the effectiveness of extensive teacher preparation in producing SETs who meet full certification/licensure standards, and the ineffectiveness of lesser amounts of preparation. Compared with the percentages for beginning SETs, the fully certified percentages for beginning GETs were higher for all three amounts of teacher preparation. Given that extensive teacher preparation is designed to produce graduates who will satisfy full certification requirements set by states (NASDTEC, 2003), it might seem surprising that substantially less than $100 \%$ of beginning SETs and GETs were not fully certified. This is to be expected, however, because our definition is "fully-certified in a teacher's main teaching assignment," whereas many teachers are fully certified, but in some 
other teaching assignment (Boe \& Cook, 2006). Similarly, a large percentage of teachers are given a main teaching assignment that is out of the field of their degree major (see results in Table 1 for the teaching assignment variable). For example, an SET with a degree major and full certification in learning disabilities could be assigned to a classroom of students with behavior disorders. Since teachers typically (though not exclusively) earn certification in the teaching field of their degree major, it is not surprising that a teacher's specific assignment affects their certification status. In addition, there are a number of other reasons for beginning teachers not to be fully certified in their main teaching assignment. For example, teachers moving from one state to another may be in the process of securing full certification in the new state.

TABLE 1. Qualifications of Beginning Teachers by Teacher Preparation Status: 1999-2000

\begin{tabular}{|c|c|c|c|c|c|}
\hline \multirow[b]{2}{*}{ Qualifications of beginning teachers } & \multirow[b]{2}{*}{ Statistic $^{b}$} & \multicolumn{3}{|c|}{ Teacher preparation status ${ }^{a}$} & \multirow[b]{2}{*}{ Total } \\
\hline & & Extensive & Some & Little/None & \\
\hline \multicolumn{6}{|c|}{ Special education } \\
\hline Certification in MTA $\mathrm{A}^{\mathrm{a} e} \mathrm{e}$ & & & & & \\
\hline Fully & $\mathrm{Col} \%$ & 75.2 & 33.0 & 14.2 & 66.9 \\
\hline Partly & $\mathrm{Col} \%$ & 24.9 & 67.0 & 85.8 & 33.2 \\
\hline \multicolumn{6}{|l|}{ Field assignment ${ }^{\mathrm{a}}$} \\
\hline In-field & $\mathrm{Col} \%$ & 44.0 & 26.2 & 5.5 & 39.8 \\
\hline Out-of-field & $\mathrm{Col} \%$ & 56.0 & 73.8 & 94.5 & 60.2 \\
\hline \multicolumn{6}{|l|}{ Degrex major ${ }^{a}$} \\
\hline General education major & $\mathrm{Col} \%$ & 18.6 & $17.2^{\mathrm{d}}$ & $7.6^{\mathrm{d}}$ & 17.8 \\
\hline Special aducation major & $\mathrm{Col} \%$ & 71.9 & 32.8 & $18.0^{\mathrm{d}}$ & 64.4 \\
\hline Other major & $\mathrm{Col} \%$ & 9.5 & 50.0 & 74.4 & 17.8 \\
\hline \multicolumn{6}{|l|}{ Degrex level ${ }^{1}$} \\
\hline Master's & $\mathrm{Col} \%$ & 33.6 & 15.6 & 30.9 & 31.3 \\
\hline Bachelor's & $\mathrm{Col} \%$ & 66.4 & 84.4 & 69.1 & 68.7 \\
\hline \multicolumn{6}{|c|}{ General education } \\
\hline Certification in $\mathrm{MTA}^{\mathrm{a}, \varepsilon}$ & & & & & \\
\hline Fully & $\mathrm{Col} \%$ & 81.1 & 53.9 & 26.4 & 75.4 \\
\hline Partly & $\mathrm{Col} \%$ & 18.9 & 46.1 & 73.6 & 24.6 \\
\hline \multicolumn{6}{|l|}{ Field assignment ${ }^{\mathrm{a}}$} \\
\hline In-field & $\mathrm{Col} \%$ & 61.9 & 45.6 & 39.1 & 59.1 \\
\hline Out-of-field & $\mathrm{Col} \%$ & 38.1 & 54.4 & 60.9 & 40.9 \\
\hline \multicolumn{6}{|l|}{ Degrex major ${ }^{\mathrm{a}}$} \\
\hline General education major & $\mathrm{Col} \%$ & 68.7 & 39.5 & 14.6 & 62.8 \\
\hline Special education major & $\mathrm{Col} \%$ & 1.0 & $0.9^{d}$ & $0.6^{\mathrm{d}}$ & 1.0 \\
\hline Other major & $\mathrm{Col} \%$ & 32.1 & 59.7 & 84.8 & 36.2 \\
\hline \multicolumn{6}{|l|}{ Degrex level } \\
\hline Master's & $\mathrm{Col} \%$ & 21.3 & 18.5 & 20.8 & 21.0 \\
\hline Bachelor's & $\mathrm{Col} \%$ & 78.7 & 81.5 & 79.3 & 79.0 \\
\hline
\end{tabular}

Noic. Data from the 1999-2000 Schools and Staffing Survey, National Center for Education Statistics, U.S. Departmert of Education.

-For each of the special education teacher qualifications and first three general education teacher qualificaticns, the teacher preparation status by characteristic chisquare iest was statistically significant at the $p<.001$ level. "For each teacher qualification, the column percentages (Col \%) sum to $100 \%$ (except for rounding error) for esch teacher prepuration stabs. "MTA - main leaching assignment. ${ }^{d} x<30$.

In- and Out-of-Field Teaching Assignment. The probability of a teacher securing an in-field teaching assignment is a joint function of a teacher's degree major field and the main teaching assignment field provided by the hiring school district. The latter depends on the supply of teachers with particular degree majors available to a district and the district need to fill open 
positions by teachers who have majored in particular fields. In spite of these assignment contingencies having nothing to do with preparation, beginning SETs with extensive teacher preparation in pedagogy and supervised teaching were more likely to secure in-field teaching assignments $(44.0 \%)$ than were those with only some preparation $(26.2 \%)$ or those who were not prepared (5.5\%; see Table 1). These in-field percentages are much lower than those for beginning GETs. One reason for the much lower in-field percentage of extensively prepared SETs than GETs is that 37\% of extensively prepared first-time SETs did not have degree majors in special education. Instead, they had degrees in general education or in academic disciplines (and only about $25 \%$ of these were fully certified in their main teaching assignment in special education; Boe \& Cook, 2006). The lack of degree majors in special education is another index of the shortage of qualified teachers for positions in this field.

Degree Major Field. As also shown in Table 1, 71.9\% of beginning SETs with extensive preparation in pedagogy and supervised teaching majored in special education, while $18.6 \%$ majored in general education (i.e., these were out-of-field). These percentages of education majors would likely be even higher if some states did not prohibit an individual seeking certification from majoring in professional education instead of in an academic discipline or other field (e.g., California and Massachusetts; NASDTEC, 2003, Table B-4). The percentage of SETs with only some preparation who majored in special education was much lower (32.8\%) than SETs with extensive preparation, whereas relatively few SETs without preparation earned such majors (18.0\%). As discussed above, a major in special education contributed both to SETs securing an in-field teaching assignment and to full certification. The extent to which GETs with extensive preparation had majored in general education (68.7\%) was quite similar to that of SETs who majored in special education, though a negligible percentage of GETs majored in special education (1.0\%).

Degree Level. Of beginning SETs, for all amounts of teacher preparation combined, 31.3\% earned a master's degree (or higher; see Table 1). These beginning SETs were much more likely to earn master's degrees than were comparable GETs (31.3\% vs. $21.0 \%$, respectively). This is consistent with the results of earlier research (Boe, Cook, Kaufman, \& Danielson, 1996), which also showed that more SETs than GETs earned master's degrees. Degree level is a common indicator of teacher qualifications. For example, some states require a master's degree for second-stage teacher certification (e.g., Indiana and New York; NASDTEC, 2003, Table D1). For beginning teachers, only a bachelor's degree is required under all state certification systems (NASDTEC, 2003, Table B-1) and the NCLB definition of an HQT.

With respect to the concept of an HQT defined by NCLB and IDEIA, the results shown in Table 1 demonstrate that completing extensive preparation in pedagogy and supervised teaching matters a great deal in the attainment of two key qualifications for an HQT: full certification and in-field teaching assignments, as defined here. Beginning SETs and GETs who completed lesser amounts of teacher preparation were clearly disadvantaged in both respects.

\section{Do Teacher Reports of Being Well Prepared to Teach Vary by Amount of Teacher Preparation?}


Figure 2 shows the percentages of beginning SETs in public schools who reported being well prepared in each of seven capabilities according to amount of preparation in pedagogy and practice teaching. Statistically significant differences in the amount of preparation were found for the first four capabilities listed. Extensively prepared SETs reported being "better prepared" than were SETs with only some preparation. As might be expected, SETs without any preparation reported being the least well prepared.

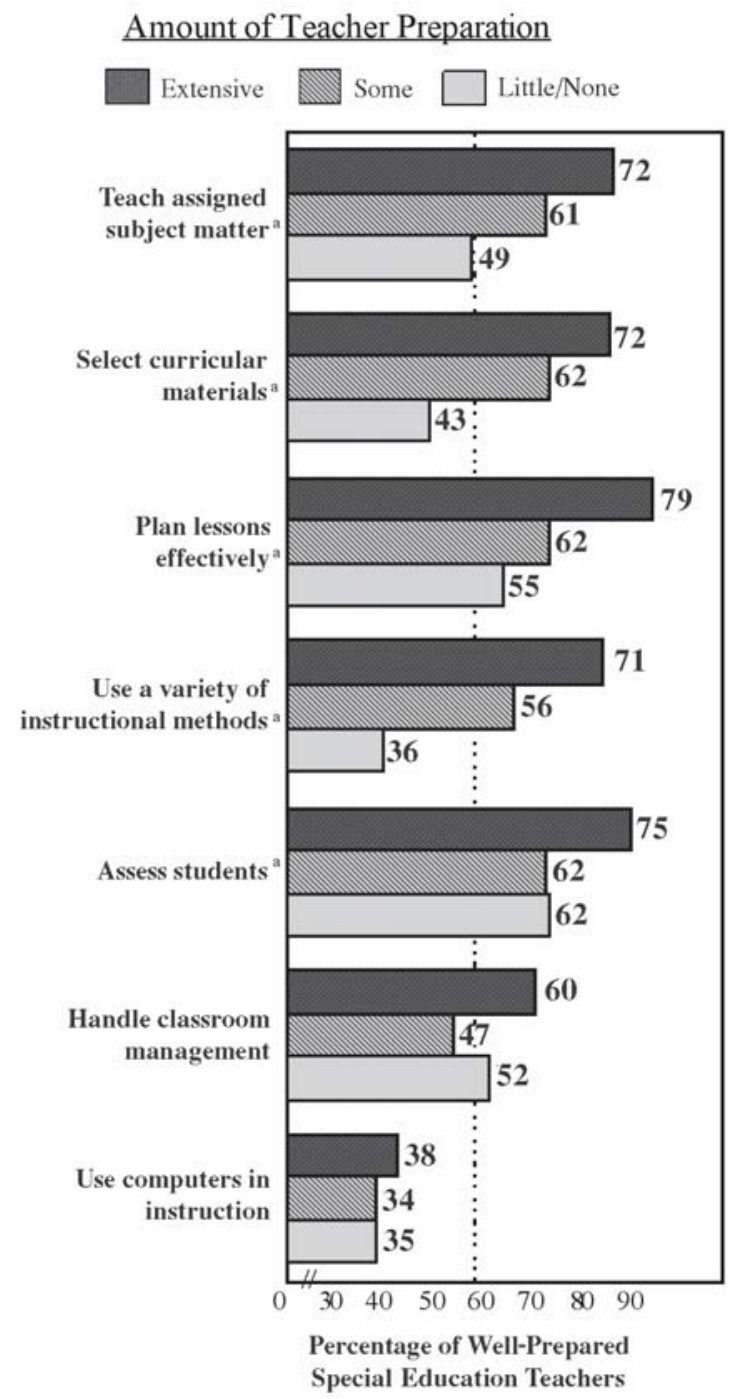

FIGURE 2. Percentage of beginning teachers in special education who reported being well prepared in each of seven categories of teaching capability by amount of preparation. For five of the seven teaching capabilities, the differences among the three amounts of teacher preparation were statistically significant at the $p<.001$ level, or greater. Data source: The 1999-2000 Schools and Staffing Survey, NCES, USDOE.

The corresponding findings for GETs are shown in Figure 3. GETs with extensive preparation similarly reported being better prepared than were GETs with only some preparation, whereas 
GETs without any preparation generally reported being the least well prepared. But do the extensively prepared SETs report being better, or not as well, prepared as comparable GETs (see Note 1)? To answer this question, it is useful to classify the six teaching capabilities into two main categories: subject matter (as represented by "teach assigned subject matter") and five pedagogical skills (select curricular materials, plan lessons effectively, use a variety of instructional methods, assess students, and handle classroom management). The seventh teaching capability (use computers in instruction) was excluded because it was not associated systematically with the amount of teacher preparation variable.

Regarding the five pedagogical skills, differences between beginning SETs and GETs with extensive preparation were less than 6 percentage points, with the higher score sometimes in favor of SETs, sometimes GETs. Thus, SETs and GETs with extensive preparation reported being about equally well prepared in pedagogical skills.

With respect to “assigned subject matter,” however, beginning GETs with extensive preparation reported being better prepared than were comparable SETs (83\% vs. 72\%, respectively; $p<.001$, two-tailed). Regardless, the reports of being well prepared in subject matter by beginning teachers in both areas were quite high in an absolute sense (i.e., at least 72\%). The difference between SETs and GETs can be interpreted as evidence that beginning SETs lag behind GETs in knowledge of subjects taught; therefore, SETs should become better prepared in the subject matter they teach - as implied by the new IDEIA definition of a highly qualified SET. On the other hand, it can be argued that most beginning SETs have sufficient subject matter knowledge for the grade levels at which they teach, and having a high level of pedagogical skills is more important.

The advantage in being well prepared to teach "assigned subject matter" held by beginning GETs with extensive preparation compared with extensively prepared SETs might be confounded with other teacher qualification variables (e.g., certification, teaching field assignment). This could account for reports by GETs of being better prepared to teach assigned subject matter than reports by SETs. In view of this possibility, logistic regression analyses were performed to determine whether these findings would hold up in multivariate models incorporating four qualification variables as potential confounders. In these analyses, the binary dependent variables were "well prepared” (coded as 1) versus "not well prepared” (coded as 0 ) for each of six teaching capabilities.

The results of these further analyses for beginning SETs are reported in Table 2 in terms of odds ratios (OR) - an effect size statistic. The top row shows the unadjusted results from bivariate logistic regression analyses assessing the associations between amount of teacher preparation and being well prepared in six teaching capabilities. As seen, the largest effect size for teachers with extensive preparation (in comparison with no teacher preparation) was observed for the pedagogical skill to "plan lessons effectively" (OR = 4.52; see Note 2), whereas a much smaller (though still substantial) effect size was observed for "teach assigned subject matter" $(\mathrm{OR}=2.22$; see Note 3$)$. These ORs express the results displayed in Figure 2 in terms of effect size. 
The lower part of Table 2 shows the adjusted results from the multivariate logistic regression analyses. They incorporate three additional teacher qualification variables: certification (partly vs. fully), field assignment (out-of-field vs. in-field), and degree major (noneducation major vs. major in a field of general education vs. major in a field of special education).

The key results from these analyses for beginning SETs demonstrate the following:

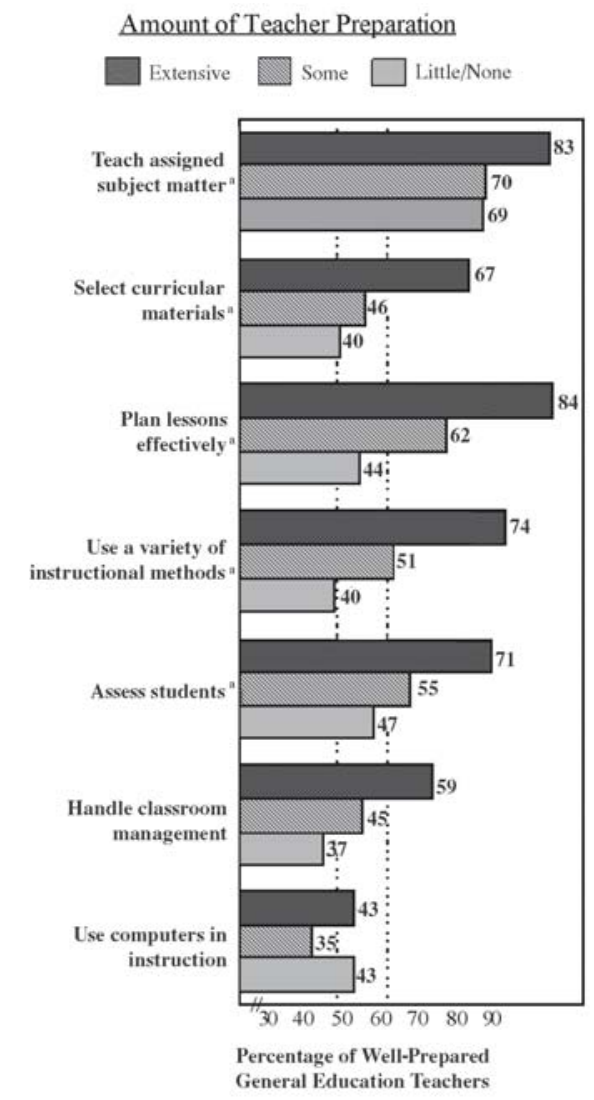

FIGURE 3. Percentage of beginning teachers in general education who reported being well prepared in each of seven categories of teaching capability by amount of preparation. For all of the seven teaching capabilities, the differences among the three amounts of preparation were statistically significant at the $p$ $<.001$ level, or greater. Data source: The 1999-2000 Schools and Staffing Survey, NCES, USDOE.

- There was only a moderate reduction in the size of the ORs for the teacher preparation variable in the multivariate models, in comparison with the bivariate models, suggesting little confounding with the other qualification variables. Further, the five statistically significant ORs for extensive teacher preparation in the bivariate models remained statistically significant in the multivariate models. Thus, extensive teacher preparation remained a strong positive predictor of teacher reports of being well prepared to teach.

- By contrast with the positive results for extensive teacher preparation, the ORs for teachers with only some teacher preparation were much lower (and few were statistically significant) in either the bivariate or multivariate models. 
- While it might have been expected that extensive teacher preparation would be strongly related to being well prepared to teach in terms of four pedagogical skills in the multivariate models, it turns out that extensive preparation was also the strongest predictor of teacher reports of being well prepared to teach assigned subject matter (multivariate OR $=1.79$ ).

- In the multivariate models, three teacher qualification variables (i.e., certification, field assignment, and degree major) were not strong or (with one exception) statistically significant predictors of any of the six dimensions of being well prepared to teach. Thus, only extensive teacher preparation was the predominant predictor of six different dimensions of teacher reports of being well prepared to teach. Yet, neither the teacher preparation nor the three other teacher qualification variables were predictive of being well prepared to handle classroom management.

The corresponding multivariate analyses for beginning GETs (seen in Table 3) produced generally similar results as those for SETs, but differed in some interesting and important ways. The key findings for beginning GETs were as follows:

- The size of the ORs for both extensive and some teacher preparation in the multivariate models was generally equivalent to those seen in the bivariate models. This contrasts with the results for beginning SETs in which a modest decline in the size of these ORs was observed in the multivariate models. Nonetheless, extensive teacher preparation was a strong positive predictor of teacher reports of being well prepared to teach for both GETs and SETs.

TABLE 2. Beginning Teachers in Special Education (1995-1999): Logistic Regression Models for Predicting Teacher Judgments of Being Well Prepared Versus Not Well Prepared Using Teacher Qualification Variables

\begin{tabular}{|c|c|c|c|c|c|c|c|}
\hline \multirow{2}{*}{\multicolumn{2}{|c|}{$\begin{array}{l}\text { Teacher qualification } \\
\text { predictor variables }\end{array}$}} & \multicolumn{6}{|c|}{$\begin{array}{l}\text { Odds ratios }^{\mathrm{a}} \text { from regression models for six dependent variables } \\
\text { Teacher judgments of being well prepared vs. not well prepared }\end{array}$} \\
\hline & & \multirow{2}{*}{$\begin{array}{c}\text { Teach } \\
\text { assigned } \\
\text { subject matter }\end{array}$} & \multirow{2}{*}{$\begin{array}{c}\text { Select } \\
\text { curricular } \\
\text { materials }\end{array}$} & \multirow{2}{*}{$\begin{array}{c}\text { Plan } \\
\text { lessons } \\
\text { effectively }\end{array}$} & \multirow{2}{*}{$\begin{array}{l}\text { Use a variety of } \\
\text { instructional } \\
\text { methods }\end{array}$} & \multirow{2}{*}{$\begin{array}{l}\text { Assess } \\
\text { students }\end{array}$} & \multirow{2}{*}{$\begin{array}{c}\text { Handle } \\
\text { classroom } \\
\text { management }\end{array}$} \\
\hline Name & Level & & & & & & \\
\hline \multicolumn{8}{|c|}{ Bivariate modals } \\
\hline Tescher preparation & $\begin{array}{l}\text { Extensive } \\
\text { Some } \\
\text { Litle/Nonef }\end{array}$ & $\begin{array}{l}2.22^{* *} \\
1.46\end{array}$ & $\begin{array}{l}3.28^{\text {net }} \\
1.70\end{array}$ & $\begin{array}{l}4.52^{* * *} \\
2.05^{*}\end{array}$ & $\begin{array}{l}3.73^{\text {men }} \\
1.84^{*}\end{array}$ & $\begin{array}{l}2.73^{* n+k} \\
1.36\end{array}$ & $\begin{array}{l}1.07 \\
0.59\end{array}$ \\
\hline \multicolumn{8}{|c|}{ Multivariate models } \\
\hline Tescher preparation & $\begin{array}{l}\text { Extensive } \\
\text { Some } \\
\text { Little/Nonef }\end{array}$ & $\begin{array}{l}1.79^{*} \\
1.34\end{array}$ & $\begin{array}{l}2.76^{\text {He* }} \\
1.59\end{array}$ & $\begin{array}{l}3.49 * * \\
1.88 *\end{array}$ & $\begin{array}{l}3.05^{k+\infty} \\
1.72\end{array}$ & $\begin{array}{l}2.21=\pi \\
1.26\end{array}$ & $\begin{array}{l}1.04 \\
0.58\end{array}$ \\
\hline Certification & $\begin{array}{l}\text { Fully } \\
\text { Partlyc }\end{array}$ & 1.14 & 1.06 & 0.98 & 1.22 & 1.18 & 1.02 \\
\hline Assignment & $\begin{array}{l}\text { In-field } \\
\text { Out-of-field }\end{array}$ & 1.35 & 1.35 & $1.52^{*}$ & 1.00 & 1.10 & 1.02 \\
\hline Degree major & $\begin{array}{l}\text { Special education } \\
\text { General education } \\
\text { Other }\end{array}$ & $\begin{array}{l}1.10 \\
1.25\end{array}$ & $\begin{array}{l}1.17 \\
1.00\end{array}$ & $\begin{array}{l}1.27 \\
1.49\end{array}$ & $\begin{array}{l}1.23 \\
1.13\end{array}$ & $\begin{array}{l}1.32 \\
0.94\end{array}$ & $\begin{array}{l}1.06 \\
0.95\end{array}$ \\
\hline
\end{tabular}

Note. Data from the 1999-2000 Schools and Staffing Survey, National Center for Education Statistics, U.S. Department of Education. Ratio of the chances (i.e., odds) of being well prepared to the chances of being not well prepared in each of six teaching capabilities. The binary dependent variables were six teaching capabilities. Teacher responses of how well prepared they were in terms of each capability were coded as follows: well prepared $=1$; not well prepared $=0$. The teacher qualification predictor variables were all treated as indicator variables with the lower level listed as the reference category coded as " 0. ." The other (comparison) levels were each coded as “1." *p $<.05 .{ }^{*} p<.01 .{ }^{* *} p<001$. 
- By contrast with the positive results for extensive teacher preparation, completing only some teacher preparation was a much weaker predictor for beginning GETs. In addition, the sizes of the ORs for GETs with only some preparation were consistently smaller across the six dimensions of being well prepared to teach than for comparable SETs. Because the sizes of these SET-GET differences were only moderate, little should be inferred from them without more extensive evidence.

- As might be expected for beginning GETs, infield teaching assignment was a relatively strong predictor $(\mathrm{OR}=1.80)$ of being well prepared to teach assigned subject matter. With respect to this outcome, extensive teacher preparation was a comparably strong predictor $(\mathrm{OR}=$ 1.70). Thus, contrary to implications by the USDOE (2002), extensive teacher preparation does matter, as well as subject matter knowledge, for GETs becoming well prepared to teach academic content.

- Beginning GETs earning a major in a field of teacher education (either in general or special education) were slightly less likely to report being well prepared to "teach assigned subject matter" than were teachers earning a major in other fields (OR $=0.77$ for general education majors; OR = .75 for special education majors). Insofar as being prepared to teach subject matter, this finding is consistent with the policy of many states to prohibit teachers from earning professional education degrees (NASDTEC, 2003). No such disadvantage in earning a professional education degree was observed for beginning SETs.

- By contrast with SETs, extensive teacher preparation for GETs was predictive of being well prepared to handle classroom management.

- For beginning GETs, the three teacher qualification variables (i.e., certification, field assignment, and degree major) were not substantial (though some were statistically significant) predictors of being well prepared in any of the five pedagogical skills.

- Overall, the results of our multivariate analyses demonstrated that extensive teacher preparation in pedagogy and supervised teaching mattered a great deal in terms of reports by SETs of being well prepared in four pedagogical skills (five for GETs), whereas lesser amounts of preparation mattered little. With respect to being well prepared to teach subject matter, extensive teacher preparation mattered most for beginning SETs and GETs.

\section{Conclusion}

The results of this research are directly relevant to the USDOE contention that teacher training programs are failing to produce the highly qualified teachers that NCLB requires (USDOE, 2002). The two key requirements defining HQTs in NCLB are full state certification and a high level of content knowledge (USDOE). Regarding full certification (i.e., excluding waivers, emergency certificates, and the like), our results based on national data clearly demonstrate that teachers with extensive preparation in pedagogy and practice teaching earned a much higher level of full certification than did those with little/no preparation. As should be expected, extensive teacher preparation clearly mattered a great deal in satisfying this basic HQT requirement. Regarding content knowledge, our results likewise showed that beginning GETs with extensive preparation in pedagogy and supervised teaching were more likely to be teaching in the field of their subject matter expertise than were those with little/no such preparation. With respect to SETs, by contrast, we defined in-field teaching in terms of the correspondence between their major in special education and their main teaching field defined by the disability status of students taught, as is common in special education (the definition used by Seastrom et al., 2002). In this respect, extensive teacher preparation for SETs mattered in securing in-field 
teaching assignments. However, NCLB and IDEIA define teaching field for all teachers (SETs included) in terms of subject matter taught and require all teachers to demonstrate a high level of subject matter knowledge in each subject taught (see Note 4). Thus, the definition of in-field teaching for SETs used in our research does not conform to the NCLB definition, and it should not be interpreted as such. Nonetheless, for GETs, extensive teacher preparation clearly mattered (and was not a liability) in satisfying this basic requirement of an HQT.

TABLE 3. Beginning Teachers in General Education (1995-1999): Logistic Regression Models for Predicting Teacher Judgments of Being Well Prepared Versus Not Well Prepared Using Teacher Qualification Variables

\begin{tabular}{|c|c|c|c|c|c|c|c|}
\hline \multirow{2}{*}{\multicolumn{2}{|c|}{$\begin{array}{l}\text { Teacher qualification } \\
\text { predictor variables }\end{array}$}} & \multicolumn{6}{|c|}{$\begin{array}{l}\text { Odds ratios } \text { from regression models for six dependent variables }^{\text {b: }} \\
\text { Teacher judgments of being well prepared vs. not well prepared }\end{array}$} \\
\hline & & \multirow{2}{*}{$\begin{array}{c}\text { Teach } \\
\text { assignod } \\
\text { subject matter }\end{array}$} & \multirow{2}{*}{$\begin{array}{c}\text { Seloct } \\
\text { curricular } \\
\text { materials }\end{array}$} & \multirow{2}{*}{$\begin{array}{c}\text { Plan } \\
\text { lessons } \\
\text { effectively }\end{array}$} & \multirow{2}{*}{$\begin{array}{l}\text { Use a variety of } \\
\text { instructional } \\
\text { methods }\end{array}$} & \multirow{2}{*}{$\begin{array}{l}\text { Assess } \\
\text { students }\end{array}$} & \multirow{2}{*}{$\begin{array}{c}\text { Handle } \\
\text { classroom } \\
\text { management }\end{array}$} \\
\hline Name & Level & & & & & & \\
\hline \multicolumn{8}{|c|}{ Bivariate models } \\
\hline Teacher preparation & Extensive & $1.78^{\mathrm{m}}$ & $2.47^{*+\infty}$ & $5.90^{\circ * *}$ & $3.24^{* 2 * e}$ & $2.63^{*+\cdots e}$ & $2.39 \div$ \\
\hline & $\begin{array}{l}\text { Some } \\
\text { Little/None }\end{array}$ & 1.11 & 1.16 & $1.95^{* * *}$ & $1.19^{* * *}$ & $1.27^{*}$ & $1.25^{*}$ \\
\hline \multicolumn{8}{|c|}{ Multivariate models } \\
\hline Teacher preparation & $\begin{array}{l}\text { Extensive } \\
\text { Some } \\
\text { Little/None }\end{array}$ & $\begin{array}{l}1.70^{\text {en** }} \\
1.12\end{array}$ & $\begin{array}{l}2.57^{* * e} \\
1.19\end{array}$ & $\begin{array}{l}4.82^{* * *} \\
1.79 * * *\end{array}$ & $\begin{array}{l}3.57^{* * * 6} \\
1.44^{* * *}\end{array}$ & $\begin{array}{l}2.63^{* * *} \\
1.28^{*}\end{array}$ & $\begin{array}{l}2.47^{* * *} \\
1.24^{*}\end{array}$ \\
\hline Certification & $\begin{array}{l}\text { Fully } \\
\text { Partlye }\end{array}$ & $1.19^{\text {** }}$ & 0.92 & $1.33^{\circ}$ & 1.04 & $1.13^{*}$ & 0.95 \\
\hline Assignment & $\begin{array}{l}\text { In-field } \\
\text { Out-of-fielde }\end{array}$ & $1.80^{\operatorname{ces}}$ & 1. $12^{*}$ & $1.31^{*}$ & 1.04 & $1.13^{*}$ & 0.95 \\
\hline Degree major & $\begin{array}{l}\text { Special education } \\
\text { General education } \\
\text { Other }^{c}\end{array}$ & $\begin{array}{l}0.75 \\
0.77^{* e *}\end{array}$ & $\begin{array}{l}1.32 \\
0.92\end{array}$ & $\begin{array}{l}1.09 \\
1.20^{* *}\end{array}$ & $\begin{array}{l}1.17 \\
1.02\end{array}$ & $\begin{array}{l}1.20 \\
0.96\end{array}$ & $\begin{array}{l}1.14 \\
1.07\end{array}$ \\
\hline
\end{tabular}

Note. Data from the 1999-2000 Schools and Staffing Survey, National Center for Education Statistics, U.S. Department of Education. Ratio of the chances (i.e., odds) of being well prepared to the chances of being not well prepared in each of six teaching capabilities. The binary dependent variables were six teaching capabilities. Teacher responses of how well prepared they were in terms of each capability were coded as follows: well prepared $=1$; not well prepared $=0$. The teacher qualification predictor variables were all treated as indicator variables with the lower level listed as the reference category coded as " 0. ." The other (comparison) levels were each coded as “1." *p $<.05 .{ }^{* *} p<.01 .{ }^{* * *} p<001$.

In addition, both SETs and GETs with extensive preparation reported being better prepared to teach assigned subject matter than did those with little/no preparation. Thus, as regards the two central components of the definition of an HQT (full certification and a high level of content knowledge in one's teaching assignment), completing extensive preparation in pedagogy and supervised teaching contributed a great deal to preparing qualified beginning SETs and GETs. In these important respects, de-emphasizing instruction in pedagogy and supervised teaching (as advocated by the USDOE) would likely be counterproductive in producing a national force of HQTs. This is not to imply that improvements in the character and quality of teacher preparation are not needed. On the contrary, many have advanced visions for dramatic transformation of teacher education (e.g., Finn, 1999; National Commission on Teaching and America's Future, 1996; The Teaching Commission, 2004).

The results of our research also demonstrate that the amount of teacher preparation was associated with the field of degree major and being prepared to teach in terms of several 
pedagogical skills. With respect to the field of degree major, beginning SETs with extensive preparation were much more likely to have majors in special education than in other fields (and therefore were teaching in the field of their preparation). However, a notable finding was that almost one in five extensively prepared SETs had majored in general education (and therefore was teaching out-of-field), whereas very few GETs had majored in special education. This clearly suggests a shortage of beginning teachers prepared in special education to fill positions in this field.

The results also provided strong and consistent evidence that extensively prepared SETs and GETs were more likely to report being better prepared in pedagogical skills (i.e., selecting curricular materials, planning lessons effectively, using a variety of instructional methods, and assessing students). The value of using "well prepared to teach" variables for studying teacher quality is supported by the results of a large-scale factor analytic study of teacher quality by Carlson, Lee, and Schroll (2004). They identified a self-efficacy factor as one of five teacher quality factors and described it in terms of teacher perceptions of their skill in performing a variety of instructional tasks. This is very similar to the "well prepared to teach" variables we analyzed with SASS data.

This research provides the first national information specifically on relationships between the amount of teacher preparation and various indicators of teacher qualifications. Since these results are based on large national-probability samples of teachers, they should not be generalized to state or local levels, or to particular teacher preparation programs, unless supported by other data at the relevant level. Likewise, the research reported here was based on beginning SETs and GETs (with 1-5 years of teaching experience). The results might be somewhat different if based on first-year teachers or on more experienced teachers. It is possible that differences seen here in the relative effectiveness of different amounts of teacher preparation will diminish as the less effective beginning teachers gain more on-the-job experience, benefit from professional development, and/or leave teaching employment at higher rates. These possibilities warrant further study.

Indeed, much further research is needed to understand the relationships between teacher preparation and quality. Broad frameworks for conceptualizing the many facets of needed research have been provided by Wilson, Floden, and Ferrini-Mundy (2001) for general education and by Brownell, Ross, Colon, and McCallum (2005) for special education. From the perspective of our research, there are several avenues of research that might productively be pursued with more extensive data from the 2003-2004 SASS (when available). For example, one set of studies should examine the effects of amount of preparation in pedagogy and supervised teaching (extensive, some, little/none) by broad type (TTP,ATP, none) in a factorial design including the possibility of an interaction. It might be that type is less important than amount in producing qualified teachers.

Another set of studies should examine the effects of various types of teacher preparation by instructional level (elementary, middle, and secondary). Whitehurst (USDOE, 2003, Appendix A) concluded from his review of relevant research that content knowledge was particularly important "in advanced math and science courses in which the teacher's content knowledge is presumably more critical” (Appendix A, p. 45). Short-term ATP programs with little pedagogical 
content might be appropriate for career changers in mathematics and science at the secondary level, whereas TTP programs that have a substantial emphasis on instruction in pedagogy and practice teaching might be most appropriate at the elementary level, where advanced content knowledge is not critical.

Similarly, a further set of studies should examine the effects of various types of teacher preparation by field (special vs. general education), as recognized by Brownell et al. (2005). Sindelar et al. (2004) suggested that teacher pedagogical knowledge is especially important for instructing students with disabilities who do not learn readily. Therefore, TTP programs may be preferred over most ATP programs for SETs because they typically provide much more instruction in pedagogy. Of course, some ATP programs are designed specifically for preparing SETs, and some provide extensive preparation in pedagogy. As Sindelar et al. observed, the combination of program elements is more important than the route.

Even though both TTP and ATP programs are able to produce effective teachers, efforts to diminish the value and importance of TTP instead of to improve it are shortsighted simply because this route has and (as predicted by former Secretary of Education Paige) "will always produce a large percentage of our teachers” (Paige, 2004, p. v). Accordingly, traditional programs offered by colleges and universities represent a huge enterprise nationally, endorsed and supported by all states. Collectively they represent a significant national asset worthy of improvement.

\section{AUTHORS' NOTE}

Support for this research was provided by a grant (H0324C020002) from the Research and Innovation to Improve Services and Results for Children with Disabilities Program (Field Initiated Research Projects, CFDA Number: 84-024C), Research to Practice Division, Office of Special Education Programs, the U.S. Department of Education, to Erling E. Boe at the University of Pennsylvania; and by the Center for Research and Evaluation in Social Policy, the Graduate School of Education of the University of Pennsylvania.

\section{NOTES}

1. The same question can be asked about comparing beginning SETs and GETs with only some preparation versus no preparation. Such differences are generally not statistically significant due to much smaller sample sizes (and therefore relatively large standard errors).

2. $\mathrm{OR}=4.52$ for extensively prepared teachers means that the chances of extensively prepared teachers reporting being well prepared "to plan lessons effectively" was more than four times as great as the chances of teachers without any preparation reporting being well prepared in this respect.

3. It is noteworthy that the smallest effect size $(\mathrm{OR}=1.07)$ seen in Table 3 was for "handle classroom management.” In this respect, extensively prepared beginning SETs reported being no better prepared than were SETs without any preparation. 
4. Note the exception that teachers of core academic subjects exclusively for middle and high school students with severe cognitive disabilities need only the subject matter knowledge expected of elementary school teachers.

\section{REFERENCES}

Boe, E. E., \& Cook, L. H. (2006). The chronic and increasing shortage of fully-certified teachers in special and general education. Exceptional Children, 72, 443-460.

Boe, E. E., Cook, L. H., Kaufman, M. J., \& Danielson, L. (1996). Special and general education teachers in public schools: Sources of supply in national perspective. Teacher Education and Special Education, 19, 1-16.

Boe, E. E., Shin, S., \& Cook, L. H. (2005). Does teacher preparation matter for beginning teachers in either special or general education? (Research Rep. 2005-TSD3). Philadelphia: University of Pennsylvania, Graduate School of Education, Center for Research and Evaluation in Social Policy. (Available at http://www.gse.upenn.edu/cresp/)

Brownell, M. T., Hirsch, E., \& Seo, S. (2004). Meeting the demand for highly qualified special education teachers during severe shortages: What should policymakers consider? The Journal of Special Education, 38, 56-61.

Brownell, M. T., Ross, D. D., Colon, E. P., \& McCallum, C. L. (2005). Critical features of special education teacher preparation: A comparison with general teacher education. The Journal of Special Education, 38, 242-252.

Carlson, E., Lee, H., \& Schroll, K. (2004). Identifying attributes of high quality special education teachers. Teacher Education and Special Education, 27, 350-359.

Darling-Hammond, L., Chung, R., \& Frelow, F. (2002). Variation on teacher preparation: How well do different pathways prepare teachers to teach? Journal of Teacher Education, 53, 286302.

Darling-Hammond, L., Holtzman, D. J., Gatlin, S. J., \& Heilig, V. (2005). Does teacher preparation matter? Evidence about teacher certification, Teach for America, and teacher effectiveness. Retrieved July 13, 2005, from http://www.teachingquality.org/resources/topicalindex.htm

Darling-Hammond, L., \& Youngs, P. (2002). Defining "highly qualified teachers": What does “scientifically-based research” actually tell us? Educational Researcher, 31(9), 13-25.

Feistritzer, C. E. (2005). Alternative teacher certification: A state-by-state analysis 2005. Washington, DC: National Center for Education Information.

Finn, C. E., Jr. (1999). Foreword. In M. Kanstoroom \& C. E. Finn, Jr. (Eds.), Better teachers, better schools (pp. v-vii). Washington, DC: Thomas B. Fordham Foundation. 
Goldhaber, D. D., \& Brewer, D. J. (1999). Teacher licensing and student achievement. In M. Kanstoroom \& C. E. Finn, Jr. (Eds.), Better teachers, better schools (pp. 83-102). Washington, DC: Thomas B. Fordham Foundation.

Individuals with Disabilities Education Improvement Act of 2004, 20 U.S.C. § 1400 et seq. (2004)(reauthorization of the Individuals with Disabilities Education Act of 1990)

Laczko-Kerr, I., \& Berliner, D. C. (2002). The effectiveness of “Teach for America” and other under-certified teachers on student academic achievement:

A case of harmful public policy. Education Policy Analysis Archives, 10(37). Retrieved July 13, 2005, from http://epaa.asu.edu/epaa/ v10n37

National Association of State Directors of Teacher Education and Certification. (2003). The NASDTEC manual on the preparation and certification of educational personnel 2003 (8th ed.). Sacramento, CA: School Services of California.

National Commission on Teaching and America's Future. (1996). What matters most: Teaching for America's future. Washington, DC: Author.

No Child Left Behind Act of 2001, 20 U.S.C. $70 \S 6301$ et seq. (2002)

Nougaret, A. A., Scruggs, T. E., \& Mastropieri, M. A. (2005). Does teacher education produce better special education teachers? Exceptional Children, 71, 217-229.

Paige, R. (2004). Foreword. In U.S. Department of Education, Alternative routes to teacher certification (pp. v-vi). Washington, DC: Author.

Rosenberg, M. S., \& Sindelar, P. T. (2005). The proliferation of alternative routes to certification in special education: A critical review of the literature. The Journal of Special Education, 39, $117-127$.

Seastrom, M. M., Gruber, K. J., Haeke, R., McGrath, D. J., \& Cohen, B. A. (2002). Qualifications of the public school teacher workforce: Prevalence of out-of-field teaching 198788 to 1999-2000 (NCES 2002-603). Washington, DC: National Center for Education Statistics, U.S. Department of Education.

Sindelar, P. T., Daunic, A., \& Rennells, M. S. (2004). Comparisons of traditionally and alternatively trained teachers. Exceptionality, 12, 209-223.

The Teaching Commission. (2004). Teaching at risk: A call to action. New York: Author.

Tourkin, S. C., Pugh, K. W., Fondelier, S. E., Parmer, R. J., Cole, C., Jackson, B., et al. (2004). 1999-2000 Schools and Staffing Survey (SASS) data file user's manual (NCES 2004-303). Washington, DC: U.S. Department of Education. 
U.S. Department of Education. (2002). Meeting the highly qualified teachers challenge: The secretary's annual report on teacher quality. Washington, DC: Author.

U.S. Department of Education. (2003). Meeting the highly qualified teachers challenge: The secretary's second annual report on teacher quality. Washington, DC: Author.

U.S. Department of Education. (2004). Improving teacher quality state grants: Non-regulatory guidance. Washington, DC: Author.

Walsh, K. (2001). Teacher certification reconsidered: Stumbling for quality. Baltimore: Abell Foundation.

White House. (2002). A quality teacher in every classroom: Improving teacher quality and enhancing the profession. Retrieved May 13, 2002, from

http://www.whitehouse.gov/infocus/education/teachers

Wilson, S. M., Floden, R. E., \& Ferrini-Mundy, J. (2001). Teacher preparation research: Current knowledge, gaps, and recommendations: A research report prepared for the U.S. Department of Education. Seattle: Center for the Study of Teaching and Policy, University of Washington. 